NBER WORKING PAPER SERIES

\title{
COLLAPSING EXCHANGE RATE REGIMES:
}

SHOCKS AND BIASES

\section{Linda S. Goldberg}

Working Paper No. 2702

\section{NATIONAL BUREAU OF ECONOMIC RESEARCH \\ 1050 Massachusetts Avenue \\ Cambridge, MA 02138 \\ September 1988}

This research is part of NBER's research program in International studies. Any opinions expressed are those of the author not those of the National Bureau of Ecoomic Research. 
NBER Working Paper \#2702

September 1988

\section{COLLAPSING EXCHANGE RATE REGIMES: SHOCKS AND BIASES}

\section{ABSTRACT}

Patterns in domestic credit creation stemming from inconsistent fiscal policies have received widespread attention for aggrevating speculative attacks on central b: $k$ foreign exchange reserves and contributing to the collapse of exchange rate regimes. This paper acknowledges the importance of monetary and fiscal discipline, but also emphasizes the importance of other random shocks to the domestic money market, most notably shocks from external credit supplies and relative prices.

Policies of the domestic fiscal authorlties are only partial catalysts for speculative attacks on a currency. Expansion of domestic credit stemming from the monetization of fiscal imbalances may be dominated by involuntary domestic credit expansions necessitated by surprise shortages in supplies of external capital. Further, the unexpected availability of external capital translates into a lower net critical reserve floor, making the depletion of central bank reserves by a speculative attack more difficult to accomplish. Also of considerable importance are relative price shocks which directly influence the probability of collapse by randomizing the demand for nominal money balances.

Empirical studies of exchange rate crises that neglect these considerations will produce biased estimates of both expected collapse probabilities and anticipated post-collapse exchange rates. 


\section{INTRODUCTION ${ }^{1}$}

The importance of exchange rate crises has been emphasized in a growing body of theory concerned with sustainable policies and stabilization. Models of exchange rate crises typically depict deficits in the balance of payments leading to a gradual erosion of central bank reserves followed by a sharp, generally self-fulfilling speculative attack on the currency which succeeds at collapsing the exchange regime. The timing and magnitude of such an attack is a function of general expected profitability of such actions. Expectations of profitability are taken over the trend changes in relevant economic variables and over the range of shocks that can affect the expected money market equilibrium and, in turn, the exchange rate that would exist if an attack were to collapse the exchange regime. Patterns in domestic credit creation stemming from inconsistent fiscal policies have received widespread attention for contributing to speculative attacks on a currency. ${ }^{2}$ In this paper I acknowledge the importance of monetary and fiscal discipline, but also emphasize the importance of other random shocks to the domestic money market, most notably shocks from external credit supplies and relative prices. Policies of the domestic fiscal authorities are only partial catalysts for speculative attacks on a currency. Voluntary or choice expansion of domestic credit may be dominated by involuntary domestic credit expansions necessitated by surprise shortages in supplies of

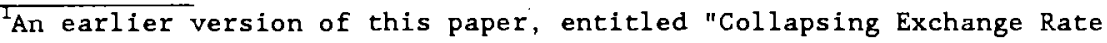
Regimes: An Extended Framework", benefited from comments and suggestions by Peter Kenen, Bill Branson, Bob Cumby, Sue Collins and an anonymous referee. Support from the C.V.Starr Center of New York University is gratefully acknowledged.

${ }^{2}$ See Krugman (1979) and Flood and Garber (1984).
} 
external capital. Further, the unexpected availability of external capital translates into a lower net critical reserve floor, making the depletion of central bank reserves by a speculative attack more difficult to accomplish. Also of considerable importance are relative price shocks which directly influence the probability of collapse by randomizing the demand for nominal money balances.

The paper emphasizes that empirical studies of exchange rate crises that neglect these considerations will produce biased estimates of both expected collapse probabilities and anticipated post-collapse exchange rates. Since these estimation biases are one of the central themes of this paper, the starting point of the theoretical exposition is the most frequently applied collapse mode1: the linear discrete-time model of Flood and Garber (1984). Applications of this basic model have generated estimates of collapse probabilities and expected post-collapse exchange rates that are overstated to the extent that they have ignored the importance of: 1) nontraded goods in the domestic consumption basket; 2) positive and significant risk premia; 3) systematic deviations from purchasing power parity (leading to relatively costly domestic nontraded goods and potentially cheap exports); and 4) significant real income effects and currency substitution motives in the demand for real money balances. Collapse probability estimates will be understated to the extent that random behavior characterizes: 1) the price of traded goods relative to nontraded goods; and 2) the availability of external credit supplies. The paper is organized as follows. Section 2 extends the Flood and Garber (1984) linear discrete time model of a collapsing fixed exchange rate, introducing a range of stochastic variables. Section 3 uses 
comparative statics to calculate the extent of probability and postcollapse exchange rate biases in estimation induced by faulty specification. Section 4 concludes.

\section{THE EXTENDED MODEL}

Models of exchange rate crises and collapsing exchange rate regimes depict deficits in the balance of payments leading to a gradual erosion and then sharp speculative attack on central bank foreign exchange reserves. This depletes reserves to the lowest level acceptable to the central bank and eliminates the means by which the government can intervene in the foreign exchange market. As in the Mexican and Argentine experiences, when this occurs the overvalued exchange rate can no longer be sustained and the exchange regime collapses. The collapse can take the form of either a discrete devaluation of the controlled exchange rate or a switch to a floating exchange rate generally accompanied by a sharp currency depreciation.

Following Salant and Henderson's (1978) application of a Hotelling model of natural resource depletion to a speculative attack on government gold stocks, Krugman (1979) applied the speculative attack model to the forefgn exchange market. Krugman showed that when future government policy is known with certainty, a balance of payments problem passes through three stages: a perlod of gradually declining reserves, a sudden speculative attack and a post-crisis period during which the currency is allowed to depreciate. When monetary policy and the quantity of reserves that the government is willing to commit to maintain the existing exchange rate are not known, the timing and magnitude of the speculative attack are dependent upon the estimates of individuals who have incomplete knowledge. 
The contribution of random domestic credit creation to the speculative attack was also the driving force in Flood and Garber's (F-G) linear discrete time model of a collapse. Consistent with Buiter's (1986) arguments, I note in this paper that uncertain government policy leading uncertain or excessive domestic credit expansion may not be the most important shock that can drive an economy to the brink of collapse. For this reason, I examine the relative importance of other shocks and restate the intuition behind a speculative attack.

The probability of an exchange regime collapse generally is modelled as the probability that an attack on central bank reserves will prove rewarding to speculating agents. Define the shadow exchange rate, $\overline{\mathrm{s}}_{t+1}$, as the exchange rate that would prevail in a post-collapse equilibrium. The probability of attack then is the probability that $\tilde{\mathrm{S}}_{t+1}$ will exceed $\overline{\mathrm{s}}_{t+1}$, the fixed rate. When the attack depletes reserves to a critically low level, the reserve floor $R_{c}$, speculating agents will profit by a minimum of $\left[\widetilde{S}_{t+1}-\vec{S}_{t+1}\right]$ per unit of foreign currency held.

I retain the basic form of the F-G model, with its emphasis on the money market equilibrium condition and some of its small country assumptions, but departing from F-G by introducing a nontraded good and allowing for systematic ${ }^{3}$ and random deviations between the relative price of traded and nontraded goods. The stochastic behavior of relative prices serves to randomize the demand for nominal money balances. I also add uncertain access to supplies of external credit to emphasize that overall

\footnotetext{
${ }^{3}$ Connolly and Taylor (1984) show how expectations of a devaluation, or change in exchange rate regime, can be reflected in relative prices of domestic and foreign goods. These dynamics are not modelled herein.
} 
domestic credit expansions are not always directly related to the policies of government fiscal authorities. Other problematic assumptions embedded in the F-G model and relaxed in this paper are: purchasing-power-parity, interest rate parity, and demand for real balances insensitive to income and currency substitution motives. One purpose of the analysis is to introduce greater realism into the modeling of balance of payments crises.

The public sector is comprised of a central bank and a government/fiscal authority. When the government decrees a fixed exchange rate, the central bank must match any excess supply of domestic credit with an offsetting decline in its foreign exchange reserves in order to maintain money market equilibrium. When reserves normally used for equilibrating the money market are no longer available, possibly because the speculative attack depleted reserves, the controlled exchange rate gives way to a flexible rate or a steeply devalued fixed rate."

The basic equations of the collapse model are equations 1 through 9. Equation 1 represents the demand for real balances, $i . e$. nominal money, $M_{t}$, divided by the domestic price index, $Q_{t}$. Money demand is sensitive to: exogenously given real income, $y_{t}$, through transaction demands; the nominal interest rate, $i_{t}$, through portfolio motives; and to the expected rate of depreciation of the exchange rate through the currency substitution motive. The exchange rate, $S_{t}$, is defined as domestic currency per unit of foreign exchange. All expectations are calculated using the available information set $\xi_{\mathrm{t}}$.

1) $M_{t} / Q_{t}=a_{0}-a_{1} i_{t}+a_{2} y_{t}-a_{3} E\left[S_{t+1}-S_{t}: \xi_{t}\right] / S_{t}$

"The model needs only minor modification to be applied to the case of unsustainable crawling exchange rates. 
Equation 2 represents the linkage between the domestic interest rate and the foreign interest rate, $i_{t}{ }_{t}, F-G$ assumed interest rate parity. Instead, I assume that the interest rate spread is comprised of the expected change in the exchange rate plus a wedge that I broadly interpret as a risk premium. The broad interpretation is because of interest rate distortions that arise when the government uses the interest rate as an instrument in the pursuit of policy objectives. The presence of this 'nonrisk' component of the wedge depends on the choice of interest rate to be used in estimation. This would lead to an $r_{t}$ which may diverge from the standard asset market interpretation of a risk premium. Further, since the domestic economy is rationed in its access to external credit, the perfect capital market's direct linkage between the interest rate and capital flows is severed. A theoretical argument for this break is provided by the stiglitz and Weiss type linkage between the price of credit and its supply. Empirical evidence of credit rationing to developing countries was given by Kharas (1984). Goldberg (1988) provided evidence that countries were limited in access to external credit in periods preceding exchange regime collapses.

2) $i_{t}=i \star_{t}+E\left[S_{t+1}-S_{t}: \xi_{t}\right] / S_{t}+r_{t}$

In Equation 3, the domestic price index is defined as a weighted sum of the price of domestic nontraded goods, $P_{t}$, and the domestic price of traded goods, $\mathrm{P}_{t}^{*} \mathrm{~s}_{t}$. The weight of nontraded goods in domestic expenditures, $\alpha$, is assumed exogenously given. If the marginal propensity to consume were permitted to vary, the model would need to distinguish between expenditure switching and expenditure reducing behavior resulting 
from expected changes in the exchange rate. As applied, we can interpret $1-\alpha$ as the share of consumed goods that are priced according to the law of one price, and $\alpha$ as the share of gooods whose price is determined partially by domestic conditions. This is a departure from the Flood-Garber formulation which assumed the existence of traded goods only $(\alpha-0)$ and all of which were priced according to the strict form of purchasing power parity. Subsequent empirical applications of the F-G model, including studies of Argentina and Mexico, have accepted this assumption although empirical evidence by Goldberg (1988) supports a contrary hypothesis.

3) $Q_{t}=\alpha P_{t}+(1-\alpha) P *_{t} S_{t}$

4) $P_{t} / S_{t}-P *_{t}+R^{\prime} t$

5) $\Omega^{\prime}{ }_{t}=\rho_{t}+\Omega_{t}$

The validity of various forms of PPP assumptions has been debated on both theoretical and empirical grounds. Accordingly, the specific form of the relation between domestic and foreign prices is left open-ended by equations 4 and 5 to introduce enough modelling flexibility to accomodate a range of interpretations. Equation 4 breaks the assumption of short run purchasing-power-parity (PPP) by introducing systematic and random relative price deviations summarized by $\Omega^{\prime}{ }_{t}$. Equation 5 divides these deviations into a predictable or systematic component, $\rho_{t}$, and a short run or random component, $\Omega_{t}$.

Equation 6 defines the money supply as the sum of domestic credit in circulation, $D_{t}$, and the stock of central bank foreign exchange reserves, $R_{t}$. Foreign exchange reserves are valued in domestic currency. Following

${ }^{5}$ Cumby and van Wijnbergen (1988) and Blanco and Garber (1986) respectively. 
the tendency of the literature, I do not address the type of money stock valuation concerns voiced by Buiter (1986).

6) $M_{t}^{s}=R_{t}+D_{t}$

7) $D_{t+1}=D_{t}+\mu_{t}+\epsilon_{t}$

8) $\epsilon_{\mathrm{t}}=\gamma_{\mathrm{t}}-\phi_{\mathrm{t}}$

Domestic credit creation proceeds according to a trend rate, $\mu_{t}$, reflecting expected monetary financing of basic government deficits, and is affected directly by two sources of variability. The first source, $\gamma_{t}$, is the product of unanticipated domestic government expenditures and uncertain government revenues. Flood and Garber (1984) and Krugman (1979) stress that this type of shock contributes greatly to the uncertain timing of a speculative attack and of the subsequent exchange regime collapse. For example, domestic credit creation above trend may be attributed to surprise shortages in government revenues or unanticipated expenditures for which no revenues are available. For simplicity $\gamma_{t}$ is modelled as an independent random variable. In more complex analyses, explicit sources of shocks could be addressed for even more specific results.

The second source of variability, $\phi_{t}$, stems from the uncertain availability of external credit flows into the troubled economy. Such external credit shocks have been documented by Harberger and Edwards (1982). Unanticipated domestic credit creation would occur when the government had planned to meet internal deficits by borrowing on world capital markets rather than by printing money. If external credit is suddenly scarce, a greater share of the basic budget will be monetized. $\phi_{t}>0$ are interpreted as unanticipated availability of external capital, decreasing the amount of domestic credit creation needed for meeting 
internal deficits. $\phi_{\mathrm{t}}<0$ are negative shocks indicating unanticipated restricted access to external capital leading to further increases in domestic credit creation above trend rate $\mu_{t}$. These shocks to external credit availability may be country specific or global as in the world contraction of credit to LDCs following the 1982 Mexican debt crisis. For convenience, the shocks to fiscal balance, external credit avallability and the relative price of traded and nontraded goods are modelled as independently though not identically distributed.

9) $M_{t}^{2}=M_{t}^{d}$

The money market equilibrium condition, Equation 9, will be used for tracking the movement of central bank reserve stocks under a fixed rate system or of the exchange rate under a flexible exchange rate system. If central bank reserves are not permitted to decline in response to an excess supply of domestic credit, the exchange rate would have to adjust.

Following Flood-Garber the exchange rate that would clear the money market if the currency were instantaneously allowed to (or forced to) float is called the shadow exchange rate, $\tilde{s}_{t}$. It provides a miniumum bound for the rate that would prevail if speculators attacked central bank reserves, depleted reserves to a critically low level, and forced the collapse of the exchange regime. It is interpreted as the lower bound for the post. collapse exchange rate.

The path of the shadow exchange rate is determined by applying the method of undetermined coefficients to combined equations 1 through 9 . Positing $\tilde{s}_{t}-\gamma_{0}+\gamma_{1} M_{t}$ and solving for coefficients $\gamma_{0}$ and $\gamma_{1}$, the solution for the shadow rate in period $t$ is:

10) $\left.\tilde{s}_{t}=\left\{1 / a\left\{P^{*}{ }_{t}+\alpha \Omega^{\prime}{ }_{t}\right)\right\}\left(\left(a_{1}+a_{3}\right) / a\right) \mu_{t}+M_{t}\right\}$ 
where $a=a_{0}+a_{2} y_{t}-a_{1}\left[i_{t}^{*}+r_{t}\right]$

I replace $M_{t}$ by its components, $D_{t}$ and $R_{t}$, use equations 7 and 8 to evaluate $D_{t}$ and then value reserves at the critical floor, $R_{c}$, to observe the shadow rate path described by Equation $11 .^{6}$

11) $\left.\tilde{s}_{t}=\left\{1 / a\left\{P_{t}^{*}+\alpha\left(\Omega_{t}+\rho_{t}\right)\right\}\right\}\left\{\left(a_{1}+a_{3}+a\right) / a\right\} \mu_{t}+D_{t-1}+R_{c}+\left(\gamma_{t}-\phi_{t}\right)\right\}$

Note the three random influences on the path on the shadow rate. Relative price shocks enter through the $\Omega_{t}$ term in the denominator. Positive (negative) relative price shocks weaken (heighten) the pressure of domestic credit growth on the exchange rate. Positive shocks caused by unanticipated basic deficits put upward pressure on the exchange rate. Some of this pressure could be mitigated by positive shocks to the availability of external credit. Unexpected capital inflows to the crisis country will alleviate some depreciation pressures. More importantly, notice that unexpected capital shortages put pressure on the exchange rate even when domestic fiscal policies are not problematic. It also is interesting that large enough relative price shocks can reverse the direction of the effects that $\left[\gamma_{t}-\Omega_{t}\right]$ will have on the shadow rate.

Following the literature, in this representative agent model and as assessed in period $t, \pi_{t}$, the probability that the exchange regime will collapse at the beginning of $t+l$, is the probability that the shadow rate will exceed the controlled rate in period $t+l$.

12) $\pi_{t}=\operatorname{Pr}\left\{\bar{s}_{t+1}-s_{t} \geq 0\right\}$

The rationale is straight-forward. Since the government's commitment to a controlled rate gives speculators unrestricted access to central bank

\footnotetext{
${ }^{5}$ For the float to be in place, central bank foreign exchange reserves would be at the critical minimum permissible level.
} 
foreign exchange reserves with free convertability, speculators operating in period ( $t$ ), who expect the shadow rate to exceed the controlled rate in period $(t+1)$, will purchase foreign exchange reserves at the end of period t. With all agents assumed identical, there will be a one shot attack on central bank reserves that drives reserves down to the critical floor. The collapse will occur instantly since there are no longer any resources to be applied in defense of the weak currency. Indeed, as emphasized by obstfeld (1986) though disputed by Buiter (1986) on consistency grounds, such a speculative attack may be self-fulfilling.

Using Equation 11 and replacing $\Omega^{\prime}{ }_{t+1}$ by the sum of its systematic and random components, manipulation of 12 yields:

$$
\text { 13) } \pi_{t}=\operatorname{Pr}\left\{s_{t} a \alpha \Omega_{t+1}-\gamma_{t+1}+\phi_{t+1} \leq K_{t+1}\right\}
$$

where $K_{t+1}=\left(\left(a+a_{1}+a_{3}\right) / a\right) \mu_{t}+D_{t}+R_{c, t+1}-S_{t} a\left[P_{t+1}^{*}+\alpha \rho_{t+1}\right]$

This complex probability expression needs to be evaluated based on the joint probability distribution of the summed right hand side random influences. This is a significant departure from the basic F-G model since we can have a non-zero probability of a run on reserves even when the basic budget is under control and nonrandom. Each of the three sources of randomness may be (but are not necessarily) characterized by distinct statistical distributions. If the shocks were not independently distributed, the cointegrated components would need to be identified and the weights on the independent distributions specified. For example, suppose government revenues were highly dependent on specific tariffs on raw material exports. The relative price shocks would also enter the $\gamma_{t}$ expression, and we might rewrite $\boldsymbol{\gamma}_{t+1}=\gamma^{\prime}{ }_{t+1}+\beta n_{t+1}$ where $\gamma^{\prime}{ }_{t+1}$ is the 
independent fiscal shock. To keep the presentation clear, these extensions are not included.

The components of money demand that are known with ' reasonable' certainty are collapsed into the $k_{t+1}$ term on the right hand side of the inequality. The general and specific solutions for a closed form solution for $\pi_{t}$ are derived first by setting up the system and then by assuming hypothetical distributions for the random components. I apply a convolution integral to solve for the joint distribution of the random variables. Rewriting the problem as

14) $\pi_{t}=\operatorname{Pr}\left\{z_{t+1} \leq K_{t+1}\right\}$,

the random variables have probability density functions (pdfs):

15) $Y_{1, t+1}=\gamma_{t+1}$ with pdf $f_{y_{1}}\left(Y_{1}\right)$

$Y_{2, t+1}=\phi_{t+1}$ with pdf $f_{y 2}\left(Y_{2}\right)$

$X_{t+1}=s_{t} a a \Omega_{t+1}$ with pdf $f_{x}(X)$

$Z_{t+1}=S_{t} a a \Omega_{t+1}-\gamma_{t+1}+\phi_{t+1}$ with pdf $f_{z}(z)$

$=X_{t+1}-Y_{1, t+1}+Y_{2, t+1}$

The derived formula for the probability density of $z_{t+1}$ is:

16) $f_{z}(Z)-\iint f_{x}(X)\left[1 / S_{t} a \alpha\right] f_{y 1}\left(Y_{1}\right) f_{y 2}\left(Z+Y_{1}-X\right) d Y_{1} d X$

so that

17) $\pi_{t}^{s}-\int_{-\infty}^{K(t)} f_{z}(z) d z$.

is the general form for the probability that the shadow rate will exceed the fixed rate next period where $Z$ is the previously defined weighted sum of random variables from equation 15 .

To provide a direct parallel to Flood and Garber and provide a more spectefc solution for $\pi_{t}$, I assume that the random variables follow exponential distributions. The exponential distributions are both 
analytically tractable and intuitively appealing, especially if we expect large positive shocks to domestic credit creation (and other stochastic terms) to be more likely than large negative shocks. For example, the argument that domestic nontraded goods prices are prone to larger shocks than traded goods prices is reasonable for the case of nontraded agricultural goods and traded manufactures, though may be unreasonable when there are traded raw materials. I represent $\Omega_{t+1}, \gamma_{t+1}$, and $\phi_{t+1}$ as exponentially and independently distributed with means adjusted to zero and variances of $(1 / w)^{2},\left(1 / \lambda_{1}\right)^{2}$, and $\left(1 / \lambda_{2}\right)^{2}$ respectively.

18) $\Omega_{t+1}--1 / w+\omega_{t+1}$, with $f_{x}-f_{w}$ and

$$
f_{x}\left(x_{t+1}\right)- \begin{cases}w \exp \left[-w \omega_{t+1}\right] & \text { if } \omega_{t+1} \geq 0 \\ 0 & \text { if } \omega_{t+1}<0\end{cases}
$$

19) $\gamma_{t+1}=-1 / \lambda_{1}+\nu_{1, t+1}$, with $f_{y 1}-f_{y}$ and

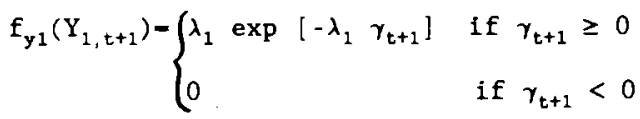

20) $\phi_{t+1}=-1 / \lambda_{2}+\nu_{2, t+1}$, with $f_{y 2}=f_{\phi}$ and

$$
f_{y 2}\left(Y_{2, t+1}\right)- \begin{cases}\lambda_{2} \exp \left[-\lambda_{2} \phi_{t+1}\right] & \text { if } \phi_{t+1} \geq 0 \\ 0 & \text { if } \phi_{t+1}<0\end{cases}
$$

Shift variables, $1 / w, 1 / \delta_{1}$ and $1 / \delta_{2}$ are included so that the random variables are distributed mean zero. Redefining $K_{t+1}$ as $K_{t+1}^{\prime}$ to include the shift variables, I integrate over equation 21 to derive the pdf of $z$.

21) $\mathrm{f}_{z}(\mathrm{Z})-\int_{0}^{0} \int_{\mathrm{z}-\mathrm{z}}^{\infty}\left(w \lambda_{1} \lambda_{2} / S_{t} a \alpha\right) \exp (-w X) \exp \left(-\lambda_{1} \mathrm{Y}_{1}\right) \exp \left[-\lambda_{2}\left(Z+\mathrm{Y}_{1}-\mathrm{X}\right)\right] d \mathrm{Y}_{1} d X$ so that

22) $\left.f_{2}(Z)-\left\{\omega \lambda_{1} \lambda_{2} / s_{t} a \alpha\left(\lambda_{1}+\lambda_{2}\right)\left(w+\lambda_{1}\right)\right\} \exp \left(\lambda_{1} z\right)\right\}$

Finally, integrating over the range of $2,\left(-\infty, K_{t+1}^{\prime}\right)$, yields 23) $\pi_{t}-\left\{\omega \lambda_{2} /\left[S_{t} a \alpha\left(\lambda_{1}+\lambda_{2}\right)\left(\omega+\lambda_{1}\right)\right]\right\} \exp \left[\lambda_{1} K_{t+1}^{\prime}\right]$ 
with $K^{\prime}{ }_{t+1}=\left(\left(a+a_{1}+a_{3}\right) / a\right) \mu_{t}+D_{t}+R_{c}-1 / \lambda_{1}+1 / \lambda_{2}-S_{t} a\left[P_{t+1}^{*}+\alpha \rho_{t+1}-\alpha / \omega\right]$

The probability of collapse is a function of the variance of prices $(1 / w)$, the variance of domestic credit $\left(1 / \lambda_{1}\right)$, the variance of external credit supplies $\left(1 / \lambda_{2}\right)$, the rate of domestic credit creation $\left(\mu_{t}\right)$, the critical reserve floor $\left(R_{c}\right)$, the share of nontraded goods in the domestic price index $(\alpha)$, domestic real income $\left(y_{t}\right)$, the existing exchange rate, systematic overvaluation of the nontraded good $\left(\rho_{t}\right)$, and some sumnary variable which will simply be called $\mathrm{X}$.

\section{Comparative Statics}

Using comparative statics I sign the sensitivity of $\pi_{t}$ to the state and control variables. As emphasized in the literature, the probability of collapse increases as domestic credit creation rises. Further, there exists some $\mu=\mu^{*}$ such that $\pi_{\mathrm{t}}\left(\mu^{*}\right)=1$ and for all $\mu<\mu^{*}, \mathrm{~d} \pi / \mathrm{d} \mu>0$ and $\mathrm{d}^{2} \pi / \mathrm{d} \mu^{2}$ $>0$, implying a concave mapping. There is not, however, a finite $\mu>0$ that satisfies $\pi_{t}(\mu)=0$. To completely eliminate the probability of collapse, $\mathrm{K}_{t+1}^{\prime}$ would have to equal $-\infty$, a condition unlikely to be achieved by contracting domestic credit. Though $\pi_{t}$ can not be eliminated, it can certainly be reduced significantly by lowering $\mu_{t}$, the trend rate of expansion of domestic credit. This would require fiscal control.

The probability of collapse is positively correlated with the variability of domestic government deficits,

$$
\begin{aligned}
& \delta \pi_{t} / \delta\left[1 / \lambda_{1}\right]>0^{7} \\
& \delta \pi_{t} / \delta\left[1 / \lambda_{2}\right]>0 \text { if } 1 / \lambda_{2} \geq 1 / \lambda_{1} \text { (sufficient condition) }
\end{aligned}
$$

The sufflcient condition $1 / \lambda_{1}<2\left[-\left(w+\lambda_{2}\right)+\sqrt{\left(w+\lambda_{2}\right)^{2}+2}\right]^{-1}$ 
and is positively correlated with the variability of supplies of external credit, as long as external credit markets are characterized by more uncertainty than internal fiscal balances.

$\pi_{t}$ is positively correlated with the degree of randomness associated with relative prices as long as $1 / w$ is sufficiently large. As the share of nontraded goods or goods not satisfying the law of one price decreases $(\alpha \rightarrow$ $0), 1 / w$ must increase $(1 / w \rightarrow \infty)$ to satisfy 26 .

$$
\begin{aligned}
& \delta \pi_{\mathrm{t}} / \delta(1 / w)>0 \text { if } 1 / w>1 / \lambda_{1}\left[\left(1-a \alpha S_{t}\right) / a \alpha S_{t}\right], \\
& \delta \pi_{t} / \delta \alpha_{t}<0
\end{aligned}
$$

$\pi_{t}$ is negatively correlated with the share of the consumption basket held in non PPP goods,

$$
\delta \pi_{\mathrm{t}} / \delta \mathbf{r}_{\mathrm{t}}<0
$$

and is negatively correlated with the 'risk premium' on domestic investments, $r_{t}$. Cautious interpretation of this result is warranted since the meaning of $r_{t}$ remains vague and its dependence on $\pi_{t}$ is possible. The negatively signed relationship is attributed to the decrease in the demand for real balances that occurs when the domestic interest rate rises. An increasse in $r_{t}$ leads to increased holdings of assets other than domestic money and consequent increases in $\pi_{t}$. If the risk premium were modelled as a function of $1 / \lambda_{1}, 1 / \lambda_{2}$, and $1 / w$, the overall responsiveness of $\pi_{t}$ to each of those variables would be reduced.

$$
\delta \pi_{\mathrm{t}} / \delta \mathrm{y}_{\mathrm{t}}<0
$$

The probability of collapse is negatively correlated with the level of real income, reflecting the increased transactions demand for real balances that reduces the excess supply of domestic credit. Intuitively an exception to this result would occur when increased $y_{t}$ spurs a more than 
proportionate worsening of the current account due to increased import demand. This effect is not captured by the model. Indeed if a fully specified economy were modelled with real income dependent on domestic spending expansions, the dynamics of the exchange rate would be considerably more complex.

$$
\delta \pi_{\mathrm{t}} / \delta \rho_{\mathrm{t}}<0
$$

As nontraded goods become systematically more expensive relative to traded goods [Connolly and Taylor (1984)] the demand for real money balances for transactions increases, alleviating pressure on the exchange rate. Implicit in this statement is the relatively inelastic demand for such nontradeables as services. As documented by Calvo (1983), such a sharp increase in the relative price of nontraded goods in Argentina occured in the two and one half years preceding the May 1981 sharp devaluation of the peso. However, if the anticipation of a devaluation shifts demand away from nontraded goods as hoarding of traded durables accelerates there would be some downward pressure on the relative price of nontraded goods.

$$
\delta \pi_{t} / \delta a_{3}<0
$$

Finally, $\pi_{t}$ is positively correlated with the leakage through currency substitution, as expected. It should be noted that a nonlinear rather than a Iinear currency substitution term would probably better represent the nature of currency substitution.

The relative magnitudes of each of the influences on $\pi_{t}$ can be quantified through the empirical study of exchange rate crises. The potential for applied research on collapsing exchange rate regimes and for application of the Flood-Garber discrete time model has been demonstrated 
by recent empirical work. Van Wijnbergen (1987) considered the sustainability of the move from a flexible to a fixed exchange rate as part of efforts to control high inflation in Brazil, Argentina and Israel. Using the Flood-Garber collapse model, van Wijnbergen illustrated the linkage between inconsistent policy measures and their post-collapse inflationary consequences. Blanco and Garber (1986) applied the basic model to the Mexican experience from 1973 to 1982 and estimated one-period ahead probabilities that the Mexican peso would collapse. Cumby and van Wijnbergen (1988) applied a similar model to the crawling peg experience of Argentina between 1979 and 1981. Despite the previously discussed troubling assumptions embedded in the basic model, these applications performed well qualitatively.

For the most part, the assumptions of the basic Flood and Garber (1984) collapse model were retained in these applications. Consequently, any collapse probability (and shadow exchange rate) estimates generated were understated to the extent that prices and external credit supplies exhibit short term randomness. Collapse probability estimates were overstated to the extent that there are: nontraded goods in the domestic consumption basket; positive and significant risk premia; systematic deviations from purchasing-power-parity; and currency substitution motives influencing the demand for real balances. Goldberg (1988) found each of these extensions statistically significant in applications to the experiences of Mexico and Argentina.

\footnotetext{
"8ee Blanco and Garber (1986), van Wijnbergen (1987), Collins (1986), Cumby and van Wijnbergen (1988), and Goldberg (1987b).
} 


\section{Concluding Remarks}

This paper has extended the Flood-Garber discrete time collapse model to include a range of random influences on the money market. Though excessive and volatile domestic credit creation generally is perceived as the primary Eorce behind a speculative attack, the reasons for domestic redit creation should be examined carefully and specifically addressed before policy prescriptions are recommended for a crisis country. It is possible that unstable external credit supplies contribute more to the onset of a speculative attack than do anticipated fiscal shortages or surpluses. Highly variable relative prices may also have a more significant role than variable domestic fiscal policies in triggering speculative attacks on sentral bank reserves.

Recent empirical applications of the basic model potentially will have biased estimates of collapse probabilities and shadow exchange rates to the extent that the extensions presented in this paper are statistically significant. 


\section{References}

Blanco,H. and P. Garber, "Recurrent Devaluation and Speculative Attacks on the Mexican Feso", Journal of Political Economy, (February 1986).

Calvo, G.A. "Trying to Stabilize: Some Theoretical Reflections Based on the Case of Argentina", in Financial Policies and the World Capital Market: The Problem of Latin American Countries, edited by Pedro Aspe, R. Dornbush and M. Obstfeld, University of Chicago Press (1983).

Connolly, M. and D. Taylor, "The Exact Timing of the Collapse of an Exchange Rate Regime and Its Impact on the Relative Price of Traded Goods", Journal of Money. Credit and Banking, vol.16, no.2 (May 1985).

Cumby, R. and $S$. van Wijnbergen, "Fiscal Policy and Speculative Runs on the Central Bank Under a Crawling Exchange Rate Regime: Argentina 19791981", National Bureau of Economic Research Working Paper no. 2376 , (September 1987).

Flood, R. and P. Garber, "Collapsing Exchange Rate Regimes: Some Linear Examples", Journal of International Economics, vol. 16 (1984).

Flood, R. and R. Hodrick, "Real Aspects of Exchange Rate Regime Choice with Collapsing Fixed Rates," Journal of International Economics vol.21, no.3/4 (November 1986).

Goldberg, L., Collapsing Exchange Rate Regimes: A Theoretical and Empirical Investigation, Ph.D.Thesis, Princeton Universicy, (January 1988).

, "Collapsing Exchange Rate Regimes: An Application to Mexico and Argentina", C.V. Starr working paper \#88-13 (1987).

, "Collapsing Exchange Rate Regimes: An Extended Framework", C.V. Starr working paper \#88-14 (1987).

Harberger, A. and S, Edwards, "Lessons of Experience Under Fixed Exchange Rates", in Theory and Experiences of Economic Development, edited by Mark Gersovitz (1982).

Krugman, P., "A Model of Balance of Payments Crises", Journal of Money. Credit and Banking, vol.11, no.3 (August 1979), 311-325.

Obstfeld, M., "Rational and Self-Fulfilling Balance of Payments Crises", American Economic Review, vol.76, no.l (March 1986).

Salant, S. and D. Henderson, "Market Anticipations of Government Policies and the Price of Gold", Journal of Political Economy vol. 86, no.4 (1978).

van Wijnbergen, S., "Fiscal Deficits, Exchange Rate Crises and Inflation", National Bureau of Economic Research working paper no. 2130 (1987). 